\title{
Clinical Investigation
}

\section{Exploring Differences in Inpatient Drug Purchasing Cost Between Two Pediatric Hospitals}

\author{
Per Nydert, MPharm ${ }^{1,2}$ and Robert Poole, PharmD ${ }^{2,3}$ \\ ${ }^{1}$ Astrid Lindgren Children's Hospital at Karolinska, Stockholm, Sweden, ${ }^{2}$ Department of Pharmacy, Lucile Packard \\ Children's Hospital at Stanford, Palo Alto, California, '3 School of Pharmacy, University of California, San Francisco, \\ California
}

\begin{abstract}
OBJECTIVES In this study, the hospital cost of purchasing drugs at two children's hospitals is explored with respect to high-cost drugs and drug classes and discussed with regard to differences in hospital setting, drug price, or number of treatments.

METHODS The purchasing costs of drugs at the two hospitals were retrieved and analyzed. All information was connected to the Anatomic Therapeutic Chemical code and compared in a Microsoft Access database. RESULTS The 6-month drug purchasing costs at Astrid Lindgren Children's Hospital (ALCH), Stockholm, Sweden, and Lucile Packard Children's Hospital at Stanford (LPCH), Palo Alto, California, are similar and result in a cost per patient day of US $\$ 149$ and US $\$ 136$, respectively. The hospital setting and choice of drug products are factors that influence the drug cost in product-specific ways.

CONCLUSIONS Several problems are highlighted when only drug costs are compared between hospitals. For example, the comparison does not take into account the amount of waste, risk of adverse drug events, local dosing strategies, disease prevalence, and national drug-pricing models. The difference in cost per inpatient day at ALCH may indicate that cost could be redistributed in Sweden to support pediatric pharmacy services. Also, when introducing new therapies seen at the comparison hospital, it may be possible to extrapolate the estimated increase in cost.
\end{abstract}

INDEX TERMS children, hospital/organization and administration, pharmaceutical preparations/economics, pharmacy service, Sweden, United States

J Pediatr Pharmacol Ther 2012;17(4):374-381

\section{INTRODUCTION}

Historically, drug expenditure in pediatric care has been stable and has not been sensitive to newly marketed drugs in the same way as adult medication care, primarily because most new drugs have not been studied in children and thus do not have an approved pediatric indication. By exploring the drug costs at our hospitals at Astrid Lindgren Children's Hospital (ALCH), Stockholm, Sweden, and Lucile Packard Children's Hospital (LPCH) at Stanford, Palo Alto, California, we have seen a rise in pediatric drug costs. This is especially true for those drugs with an annual expense greater than US $\$ 100,000$.

The Orphan Drug Act has stimulated the development of several new drugs targeted towards previously untreatable diseases, many of them unique among children. ${ }^{1,2}$ The new therapies have limited applications to small patient populations (fewer than 200,000 individuals), which results in very high production costs. While those regulations are welcomed and needed, they will also affect drug cost as new indications are introduced.

The Best Pharmaceuticals for Children acts in the United States ${ }^{3}$ and the European Pediatric Regulation ${ }^{4}$ have targeted better medicines for children by stating the need for availability of pediatric-specific drug formulations and better pediatric data. Furthermore, it is extremely difficult to design, recruit, and complete investigational drug studies in children. However, the final pediatric drug cost, which may result in safer drug use, is hard to determine. In addition, better pediatric data and pediatric-specific products can 


\section{ALCH}
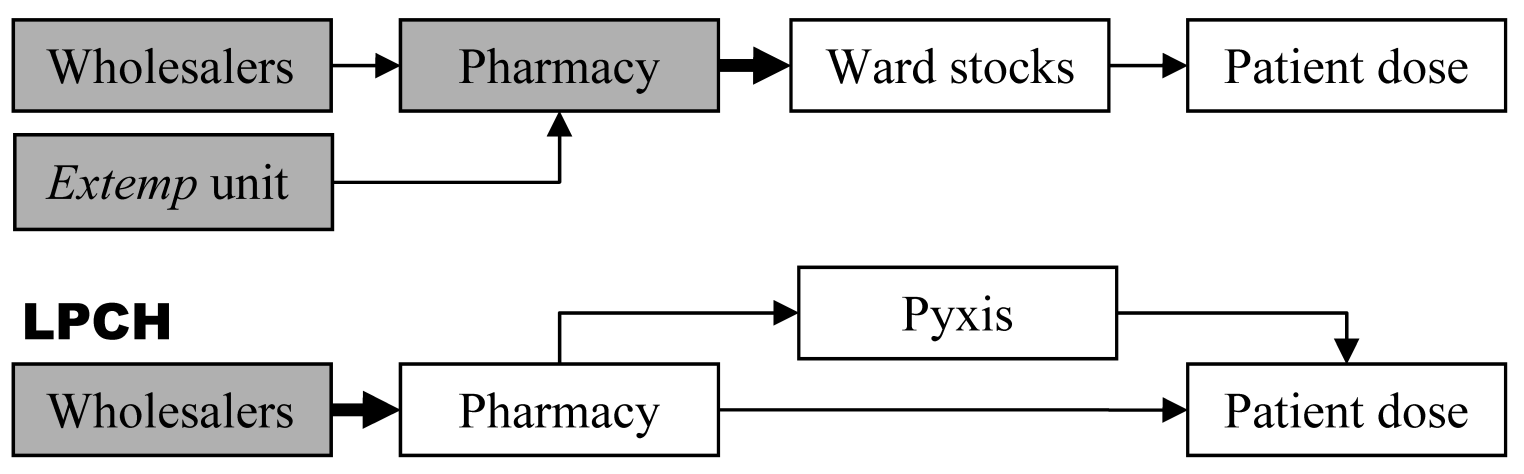

Figure. The drug-handling process at ALCH and LPCH. The bold arrows between the grey and white boxes illustrate the economic and drug product transfer that is presented in this article. ALCH, Astrid Lindgren Children's Hospital, Stockholm, Sweden; LPCH, Lucile Packard Children's Hospital at Stanford, Palo Alto, California.

reduce cost by preventing adverse drug events. ${ }^{5}$ Therefore, the final drug cost will be dependent on the whole drug delivery system within the hospital. The two hospitals that are compared have different systems for drug delivery. The major differences are that ALCH uses an adult pharmacy service, not operated by the children's hospital, that delivers mainly whole drug packages to the individual ward as floor stock, while LPCH uses a hospital-operated pediatric pharmacy that delivers patient-specific unit doses. In addition, ALCH is operated by a system whereby medical costs are covered by a single payer, while LPCH is a private, non-profit children's hospital within an insurance-based system. To compare our drug costs without weighing in on the drug delivery system, we have used the hospital-purchasing cost for buying the drugs used at our respective hospitals. As this method of comparison includes extrapolation of data and does not acknowledge all economic and institutional international differences, it should be regarded as a first attempt to identify and learn from major differences.

In this study, the purchasing of high-cost drugs at two pediatric children's hospitals is explored with regard to differences in hospital setting, drug price, and number of treatments.

\section{MATERIALS AND METHODS}

\section{Sweden}

The Xplain data system from the pharmacy company provider (Apoteket AB, Stockholm, Sweden) was used to extract the information to a spreadsheet about the cost of drugs used at the Karolinska University Hospital for all wards affiliated to the pediatric hospital for the first 6 months of 2008. The information is presented as cost of packages sold from the pharmacy to the wards (Figure). The price to the ward is calculated on the procurement cost plus a pharmacy fee per sold package. All information is connected to the Anatomic Therapeutic Chemical (ATC) code. ${ }^{6}$

\section{United States}

Data about drug procurement cost from the primary drug wholesaler, from August 2007 until July 2008, are combined with data from other drug suppliers and extracted to a spreadsheet (Figure). All generic compound data extracted are analyzed and translated into the corresponding ATC code. The drug cost is then divided by a factor of two to be comparable to the Swedish 6-month data. In addition, the LPCH wholesaler combines outpatient and inpatient pharmacy data, which requires a conversion factor to predict use among the pediatric inpatients. We used the LPCH budget for drugs to estimate that $64 \%$ of the cost is connected to the inpatient care. This estimation includes certain high-cost drugs used exclusively in either the inpatient or outpatient care areas. This factor is taken into account in the analysis of the results.

\section{Combination of Data}

All data were imported into a Microsoft Access database (San Francisco, CA). The Swedish data were converted into US dollars (USD) by using the following exchange rate: 7 Swedish krona 
Table 1. Hospital Numbers Compared for LPCH and ALCH

\begin{tabular}{|c|c|c|}
\hline & ALCH & LPCH \\
\hline Pediatric beds & 164 & 212 \\
\hline Neonatal beds & 69 & 83 \\
\hline Substances & 609 & 709 \\
\hline $\begin{array}{l}\text { Purchasing drug cost per } 6 \text { mo } \\
\text { (million USD) }\end{array}$ & 4.6 & 5.5 \\
\hline $\begin{array}{l}\text { Purchasing drug cost per patient } \\
\text { days (USD) }\end{array}$ & 149 & 136 \\
\hline Days of inpatient care per 6 mo & 31,200 & 40,300 \\
\hline Employed inpatient pharmacists & 2 & 30 \\
\hline Pharmacy owned by hospital & No & Yes \\
\hline
\end{tabular}

ALCH, Astrid Lindgren Children's Hospital, Stockholm, Sweden; LPCH, Lucile PackardChildren's Hospital at Stanford, Palo Alto, California; USD, United States dollars

$=1$ USD. All data were compared by cost per generic substance by using the corresponding ATC code on a 1-, 3-, and 7-digit ATC code level. Daily defined doses (DDDs) are not defined since proper DDDs do not exist for children. Tables of combined drug use with a cost greater than US $\$ 100,000$ for both hospitals are presented and differences in drug cost are analyzed and presented with respect to the hospital setting, drug price, or number of treatments. Drug purchases of hemophilia products and nitric oxide are excluded from this analysis.

This study did not include patient data and did not require institutional review board approval.

\section{RESULTS}

The 6-month drug purchasing costs at ALCH and LPCH are similar with a total cost of US $\$ 4.6$ and US $\$ 5.5$ million, respectively. The higher total cost at LPCH could be attributed to the larger group of patients and patient days as illustrated in Table 1. The hospital setting and choice of drug products are factors that influence the drug cost in product-specific ways. Most strikingly is the drug-purchasing cost per patient day, which is lower at LPCH. Another highlighted difference is the absence of high-cost transplant drugs (Table 2; immunosuppressant/stimulating, antiviral drugs) at ALCH, as transplant patients are transferred to the adult hospital for those procedures and subsequent care. This difference could partly be lowered by the high unspecified cost at ALCH, which is due to the procurement of ready-to-use extemporaneously prepared drugs from 1 of the 4 stand-alone units producing extemporaneous drugs in Sweden (Figure). Even if the cost of certain groups of drugs is the same, differences within each group exist. When examining drugs with similar purchasing cost in the J01 group (Table 3; antibacterials for systemic use), the cephalosporine cost is higher at ALCH, with a higher cost for ampicillin at LPCH. Different drug-pricing strategies in the two countries were also found to be a main determinant of differences in drug cost (Table 4; e.g., budesonide, surfactants, and filgrastim). Also, the choice and availability of drug products will affect the drug-purchasing cost (Table 4; e.g., intravenous [IV] ibuprofen is used for ductus closure at $\mathrm{ALCH}$, as compared to the more expensive IV indometacin used at LPCH). Other examples are IV acetaminophen, which is not available at $\mathrm{LPCH}$, and levalbuterol, not used at ALCH. The greater use of different drugs at LPCH also affects the drug cost (e.g., the use of dexmedetomidine is not seen at $\mathrm{ALCH}$ ). Both hospitals have had a patient with Hunter syndrome who was taking idursulfase; as this orphan drug has a very high drug cost, it is responsible for around 3\% to 5\% of the total drug budget.

\section{DISCUSSION}

The total annual drug expenditures are similar between the two pediatric hospitals. Comparing the total drug-purchasing cost in USD per patient day shows that LPCH has a drug-purchasing cost that is $22 \%$ lower than that of ALCH. This could be connected to a lower drug cost in a unit dose system, with a total drug cost for ALCH that is falsely low, since it does not include the high costs associated with organ transplant patients as the transplants are under the care of the adult hospital. In addition, the nursing staff level is higher at ALCH with a lower number of hospital beds, which could partly be attributed to the time-consuming process of drug reconstitutions/preparations at a pediatric ward. The lower nursing staff level at LPCH is likely due to transfer of labor into the pharmacy where dose preparation is done. However, several problems are highlighted when drug costs between hospitals are compared, for example, choice of drug treatments in the formulary, hospital setting, the amount of waste, risk 
Table 2. Difference in Drug Cost per Patient Days Compared for All Therapeutic Classes in ATC Code Level 1 for ALCH Minus LPCH

\begin{tabular}{lll}
\hline ATC Code Level 1 & $\begin{array}{c}\triangle \mathrm{ALCH}- \\
\mathrm{LPCH}, \mathbf{\$}\end{array}$ & Drug Cost Difference \\
\hline
\end{tabular}
A Alimentary tract and metabolism
B Blood and blood-forming organs

C Cardiovascular system

D Dermatologicals

G Genitourinary system and sex hormones

H Systemic hormonal preparations, excluding sex hormone, and insulin

J Anti-infectives for systemic use

L Antineoplastic and immunomodulating agents

N Nervous system

P Antiparasitic products, insecticides, and repellents

R Respiratory system

S Sensory organs

V Unspecified and various products

Total difference
1.0 The cost of idursulfase at ALCH is offset by outpatient costs for imiglucerase and alglucosidase alfa at LPCH.

12.3 Drug products contain already premixed TPN at ALCH. TPN is tailor made after ingredient procurement at LPCH.

The cost at LPCH is mainly attributed to Cathflo Activase (Genentech, South San Francisco, CA 94080), which was unavailable in Sweden. At $\mathrm{ALCH}$, if needed, coagulated ports are treated with extemporaneously prepared rt-PA.

0.0 Different pricing for several drugs. Difference mainly dependent on the higher price of IV indometacin (LPCH) versus IV ibuprofen (ALCH).

Different usage and pricing for several drugs. Main difference is the high cost of chlorothiazide at LPCH, not used intravenously at ALCH.

0.3 No impact of high-cost drugs.

-1.4 Higher usage of inpatient sildenafil and provision of anticonception pills through the outpatient setting at LPCH.

-0.0 No impact of high-cost drugs.

-1.6 The RSV treatment with palivizumab is more common in Sweden. The use of voriconazol is greater at LPCH.

The use of caspofungin is greater at $\mathrm{ALCH}$.

Transplants and patient care the first year after transplant are assumed by the adult hospital at ALCH.

Drug products contain already premixed TPN at ALCH. TPN is tailor made after ingredient procurement at LPCH.

-17.0 Transplants and patient care the first year after transplant are assumed by the adult hospital at ALCH.

Pegaspargase is used at LPCH but less at ALCH.

These products are prepared at the Swedish pharmacy before being sent to the ward (includes cost for compounding). The LPCH pharmacy also prepares the drug before it reaches the ward but this process is owned by the hospital and not included here.

10.7 In 2008 LPCH used Stanford's operating room. ALCH used more sevoflurane.

LPCH uses dexmedetomidine, which is not used at ALCH.

The use of IV paracetamol is in place at $\mathrm{ALCH}$, and IV paracetamol is not a licensed product in the United States.

-0.4 Atovaquone and pentamidine use at LPCH.

-2.8 Pulmonary surfactant is half the price at $\mathrm{LPCH}$.

LPCH pays twice the price for budesonide. ALCH does not use levalbuterol.

Dornase alfa is mainly used for outpatients at both ALCH and LPCH. The cost for LPCH shown here is mainly for the outpatient pharmacy.

0.0 Similar; usage of more anti-infective eye drops at LPCH (ciprofloxacin) and more hydrocortisone at ALCH.

11.5 Cost for drugs prepared extemporaneously at $\mathrm{ALCH}$, including sodium chloride and glucose bags from ALCH; no comparable cost is found in the LPCH material.

12.4

ALCH, Astrid Lindgren Children's Hospital, Stockholm, Sweden; ATC, Anatomic Therapeutic Chemical; IV, intravenous; LPCH, Lucile Packard Children's Hospital at Stanford, Palo Alto, California; RSV, Respiratory Syncytial Virus; rt-PA recombinant tissue Plasminogen Activator; TPN, Total Parenteral Nutrition 
Table 3. Difference in Drug Cost per Patient Days Compared for the Most Purchased Drug Classes in ATC Code Level 3 for ALCH Minus LPCH

\begin{tabular}{|c|c|c|c|}
\hline ATC & Code Level 3 & $\begin{array}{l}\triangle \mathrm{ALCH}- \\
\mathrm{LPCH}, \$\end{array}$ & Drug Cost Difference \\
\hline \multirow[t]{3}{*}{ A16 } & $\begin{array}{l}\text { Other alimentary } \\
\text { tract and metabolism } \\
\text { products }\end{array}$ & 2.0 & $\begin{array}{l}\text { Cost for } 1 \text { adolescent patient at ALCH and } 4 \text { child patients at LPCH. In } \\
\text { Sweden today the cost responsibility for idurdulfase is assumed by the } \\
\text { single-payer system so as not to burden the individual hospital. The } \\
\text { cost per package is similar if calculating an exchange rate of US } \$ 1= \\
10 \text { Sk. }\end{array}$ \\
\hline & & & $\begin{array}{l}\text { Part of the single-payer system in Sweden and prescribed mainly to } \\
\text { outpatients. The LPCH cost is attributed to the outpatient pharmacy. } \\
\text { The cost per package is similar if calculating an exchange rate of US } \$ 1 \\
=13 \mathrm{SEK} \text {. }\end{array}$ \\
\hline & & & $\begin{array}{l}\text { The cost of idursulfase at ALCH is offset by outpatient costs for } \\
\text { imiglucerase and alglucosidase alfa at LPCH. }\end{array}$ \\
\hline J06 & $\begin{array}{l}\text { Immune sera and } \\
\text { immunoglobulins }\end{array}$ & 0.1 & $\begin{array}{l}\text { Including the use of cytomegalovirus immunoglobulin at LPCH. } \\
\text { The RSV treatment with palivizumab is more common in Sweden. }\end{array}$ \\
\hline L04 & Immunosuppressants & -6.1 & $\begin{array}{l}\text { Transplants and patient care the first year after transplant are assumed } \\
\text { by the adult hospital at ALCH. }\end{array}$ \\
\hline B05 & $\begin{array}{l}\text { Blood substitutes } \\
\text { and perfusion } \\
\text { solutions }\end{array}$ & 15.6 & $\begin{array}{l}\text { Drug products contain already premixed TPN at ALCH. TPN is tailor } \\
\text { made after ingredient procurement at LPCH. }\end{array}$ \\
\hline L01 & $\begin{array}{l}\text { Antineoplastic } \\
\text { agents }\end{array}$ & -1.6 & Pegaspargase is used at LPCH but less at ALCH. \\
\hline \multirow[t]{3}{*}{ J01 } & $\begin{array}{l}\text { Antibacterials for } \\
\text { systemic use }\end{array}$ & 3.3 & $\begin{array}{l}\text { These products are prepared at the Swedish pharmacy before being } \\
\text { sent to the ward (includes cost for compounding). The LPCH pharmacy } \\
\text { also prepares the drug before it reaches the ward but this process is } \\
\text { owned by the hospital and not included here. }\end{array}$ \\
\hline & & & Slightly higher price at ALCH. \\
\hline & & & $\begin{array}{l}\text { Greater cost for cefotaxime, vancomycin, and meropenem at ALCH } \\
\text { and for piperacillin, tobramycin, ampicillin, and linezolide at LPCH. } \\
\text { ALCH does not practice unit dose, which could have impact. }\end{array}$ \\
\hline $\mathrm{J} 02$ & $\begin{array}{l}\text { Antimycotics for } \\
\text { systemic use }\end{array}$ & 1.5 & $\begin{array}{l}\text { The use of voriconazol is greater at } \mathrm{LPCH} \text {. } \\
\text { The use of caspofungin is greater at } \mathrm{ALCH} \text {. }\end{array}$ \\
\hline B01 & $\begin{array}{l}\text { Antithrombotic } \\
\text { agents }\end{array}$ & -1.7 & $\begin{array}{l}\text { The cost at LPCH is mainly attributed to Cathflo Activase (Genentech, } \\
\text { South San Francisco, CA 94080), which was unavailable in Sweden. At } \\
\text { ALCH, if needed, coagulated ports are treated with extemporaneously } \\
\text { prepared rt-PA. }\end{array}$ \\
\hline L03 & Immunostimulants & -6.8 & $\begin{array}{l}\text { Transplants and patient care the first year after transplant are assumed } \\
\text { by the adult hospital at ALCH. }\end{array}$ \\
\hline N01 & Anesthetics & 8.1 & $\begin{array}{l}\text { In } 2008 \text { LPCH used Stanford's operating room. ALCH used more } \\
\text { sevoflurane. }\end{array}$ \\
\hline $\mathrm{J} 05$ & $\begin{array}{l}\text { Antivirals for } \\
\text { systemic use }\end{array}$ & -5.8 & $\begin{array}{l}\text { Transplants and patient care the first year after transplant are assumed } \\
\text { by the adult hospital at ALCH. }\end{array}$ \\
\hline N02 & Analgesics & 4.0 & $\begin{array}{l}\text { The use of IV paracetamol is in place at ALCH, and IV paracetamol is } \\
\text { not a licensed product in the United States. }\end{array}$ \\
\hline R05 & $\begin{array}{l}\text { Cough and cold } \\
\text { preparations }\end{array}$ & -3.7 & $\begin{array}{l}\text { Dornase alfa is mainly used for outpatients at both ALCH and LPCH. } \\
\text { The cost for LPCH shown here is mainly for the outpatient pharmacy. }\end{array}$ \\
\hline R07 & $\begin{array}{l}\text { Other respiratory } \\
\text { system products }\end{array}$ & 2.2 & Pulmonary surfactant is half the price at LPCH. \\
\hline $\mathrm{C} 01$ & Cardiac therapy & 0.9 & $\begin{array}{l}\text { Different pricing for several drugs. Difference mainly dependent on } \\
\text { the higher price of IV indometacin (LPCH) versus IV ibuprofen }(A L C H) \text {. }\end{array}$ \\
\hline R03 & $\begin{array}{l}\text { Drugs for obstructive } \\
\text { airway diseases }\end{array}$ & -0.7 & $\begin{array}{l}\text { LPCH pays twice the price for budesonide. ALCH does not use } \\
\text { levalbuterol. }\end{array}$ \\
\hline N05 & Psycholeptics & -0.9 & LPCH uses dexmedetomidine, which is not used at ALCH. \\
\hline
\end{tabular}

$\overline{A L C H}$, Astrid Lindgren Children's Hospital, Stockholm, Sweden; ATC, Anatomic Therapeutic Chemical; IV, intravenous; LPCH, Lucile Packard Children's Hospital at Stanford, Palo Alto, California; RSV, definition; rt-PA, definition; SEK, Swedish krona, TPN, Total Parenteral Nutrition 
Table 4. Difference in Drug Cost per Patient Day Compared for the Most Purchased Drug Classes in ATC Code Level 7 for ALCH Minus LPCH

\begin{tabular}{|c|c|c|c|}
\hline ATC & Code Level 7 & $\begin{array}{l}\triangle \mathrm{ALCH}- \\
\text { LPCH, \$ }\end{array}$ & Drug Cost Difference \\
\hline J06BA00 & $\begin{array}{l}\text { Immunoglobulins, } \\
\text { normal human }\end{array}$ & -0.6 & Similar. \\
\hline A16AB09 & Idursulfase & 8.1 & $\begin{array}{l}\text { Cost for } 1 \text { adolescent patient at ALCH and } 4 \text { child patients } \\
\text { at LPCH. In Sweden today the cost responsibility for } \\
\text { idurdulfase is assumed by the single-payer system so as } \\
\text { not to be a burden on the individual hospital. The cost per } \\
\text { package is similar if calculating an exchange rate of US } \$ 1 \\
=10 \mathrm{SEK} \text {. }\end{array}$ \\
\hline L04AB02 & Infliximab & 4.5 & $\begin{array}{l}\text { These products are prepared at the Swedish pharmacy } \\
\text { before being sent to the ward (includes cost for } \\
\text { compounding). The LPCH pharmacy also prepares the } \\
\text { drug before it reaches the ward but this process is owned } \\
\text { by the hospital and not included here. }\end{array}$ \\
\hline J06BB16 & Palivizumab & 4.6 & $\begin{array}{l}\text { The RSV treatment with palivizumab is more common in } \\
\text { Sweden. }\end{array}$ \\
\hline L03AA02 & Filgrastim & -3.9 & $\begin{array}{l}\text { Filgrastim is } 1.7 \text { times more expensive at LPCH. A larger } \\
\text { amount is used at LPCH. }\end{array}$ \\
\hline J02AA01 & Amphotericin B & 0.8 & Similar. \\
\hline $\mathrm{J} 02 \mathrm{ACO} 3$ & Voriconazole & -2.8 & $\begin{array}{l}\text { The use of voriconazol is greater at } \mathrm{LPCH} \text {. } \\
\text { The use of caspofungin is greater at ALCH. }\end{array}$ \\
\hline B05AA01 & Albumin & 0.3 & Similar. \\
\hline J01DH02 & Meropenem & 1.3 & Slightly higher price at ALCH. \\
\hline N02BE01 & $\begin{array}{l}\text { Paracetamol } \\
\text { (acetaminophen) }\end{array}$ & 4.2 & $\begin{array}{l}\text { The use of IV paracetamol is in place at ALCH, and IV } \\
\text { paracetamol is not a licensed product in the United States. }\end{array}$ \\
\hline R05CB13 & $\begin{array}{l}\text { Dornase alfa } \\
\text { (desoxyribonuclease) }\end{array}$ & -3.2 & $\begin{array}{l}\text { Dornase alfa is mainly used for outpatients at both ALCH } \\
\text { and LPCH. The cost for LPCH shown here is mainly for the } \\
\text { outpatient pharmacy. }\end{array}$ \\
\hline J02AX04 & Caspofungin & 4.1 & $\begin{array}{l}\text { The use of caspofungin is greater at ALCH. } \\
\text { The use of voriconazol is greater at LPCH. }\end{array}$ \\
\hline B01AD02 & Alteplase & -2.6 & $\begin{array}{l}\text { The cost at LPCH is mainly attributed to Cathflo Activase } \\
\text { (Genentech, South San Francisco, CA 94080), which was } \\
\text { unavailable in Sweden. At ALCH, if needed, coagulated } \\
\text { ports are treated with extemporaneously prepared rt-PA. }\end{array}$ \\
\hline B01AB02 & Antithrombin III & 0.5 & Similar. \\
\hline A16AB02 & Imiglucerase & -2.6 & $\begin{array}{l}\text { Part of the single-payer system in Sweden and prescribed } \\
\text { mainly to outpatients. The LPCH cost is attributed to the } \\
\text { outpatient pharmacy. The cost per package is similar if } \\
\text { calculating an exchange rate of US } \$ 1=13 \text { SEK. }\end{array}$ \\
\hline J01XA01 & Vancomycin & 1.9 & $\begin{array}{l}\text { These products are prepared at the Swedish pharmacy } \\
\text { before being sent to the ward (includes cost for } \\
\text { compounding). The LPCH pharmacy also prepares the } \\
\text { drug before it reaches the ward but this process is owned } \\
\text { by the hospital and not included here. }\end{array}$ \\
\hline
\end{tabular}

ALCH, Astrid Lindgren Children's Hospital, Stockholm, Sweden; ATC, Anatomic Therapeutic Chemical; IV, intravenous; LPCH, Lucile Packard Children's Hospital at Stanford, Palo Alto, California; RSV, Respiratory Syncytial Virus; rt-PA, recombinant tissue Plasminogen Activator; SEK, Swedish krona 
of adverse drug events, local dosing strategies, disease prevalence, and national drug-pricing models. Some of these differences are illustrated in this study for the high-cost drugs. The cost of palivizumab indicates different policies, procedures, and the prevalence of respiratory syncytial virus. The choices of antifungal treatments are also very different. Differences in antibiotic usage may indicate overusage or underusage, with the associated risks of developing resistant bacteria. These differences provide interesting topics for in-depth analyses with the possibility of questioning one's own practice by comparing drug costs with those of other hospitals.

The number of doses produced is known at $\mathrm{LPCH}$, which practices unit dose dispensing but not at ALCH, which practices with a floor stock model. Without knowledge of the number of doses used, the actual total drug cost is prone to misinterpretation in pediatrics as 1 package is not always consumed within 1 year. By looking only at the high drug costs such misinterpretation can be minimized as the turnaround time for these drugs is usually less than 1 year. Hypothesizing that the drug dose used at both hospitals is 11 per patient day, which targets the number of doses at LPCH and described earlier at other institutions, ${ }^{7}$ the estimated average purchasing cost is US \$12.4 (LPCH) and US \$14 (ALCH) per dose. To evaluate the actual drug cost after dispensing fees and non-formulary drug fees, several steps need to be considered.

For the unit dose system, the relative value units (RVUs) based on time studies have been described and used to define the number of RVUs specific for each drug in the formulary. One RVU corresponds to 5 minutes of labor for the pharmacist and technician, including 0.25 minutes of management time. ${ }^{7}$ The charged drug price will also include added cost for getting the funding back from the insurance companies. For ALCH the drug charge presented here includes the procurement cost and the added pharmacy dispensing cost for whole packages (and some extemporaneously prepared drugs). Additional costs at ALCH, not included in this study, are nurse drug-dispensing time and time for managing the ward stock. The inpatient drug reimbursement at ALCH comes from a fixed price, depending on the charted ICD-10 code, and only for very expensive drugs, which include individual pricing.
By comparing the drug purchases at the two hospitals we can get an overview of the products used. The aim of this comparison was to review high-cost drugs; although products and doses used in the hospital setting are different, the drug budgets could be used interchangeably. However, the estimated lower cost per inpatient day at $\mathrm{LPCH}$ could indicate that drug preparation costs in the form of nursing labor could be redistributed at ALCH to support pediatric pharmacy services. The introduction of new therapies seen at one hospital might allow the other hospital to estimate the increase in cost at its hospital. At ALCH a project is ongoing to develop a new drug-handling process that includes drug storage in automatic dispensing systems along with a change in the drug-handling process. At LPCH a new pharmacy is being built with the expansion of the number of beds. As these changes are implemented we are determined to revisit this comparison and see how it changes over time.

DISCLOSURE The authors are employed by the institutions that are compared in this study. The authors have had full access to all the data in the study and take responsibility for the integrity of the data and the accuracy of the data analysis. The pharmacy resident was supported by a grant from the Swedish Academy of Pharmaceutical Sciences.

ABBREVIATIONS ALCH, Astrid Lindgren Children's Hospital, Stockholm, Sweden; ATC, Anatomic Therapeutic Chemical; DDDs, daily defined doses; IV, intravenous; LPCH, Lucile Packard Children's Hospital at Stanford, Palo Alto, California; RVUs, relative value units; USD, United States dollars

CORRESPONDENCE Per Nydert, MScPharm, Children's Hospital, Karolinska University Hospital, Neonatal Unit H10:2, 17176 Stockholm, Sweden, email: per.nydert@ karolinska.se

\section{REFERENCES}

1. US Food and Drug Administration. The Orphan Drug Act. http:/ / www.fda.gov/ orphan. Accessed May 13, 2009.

2. European Medicines Agency. Orphan medicinal products. 2008. http:/ / www.emea. europa.eu/htms/human/orphans/intro. htm. Accessed May 13, 2009.

3. US Food and Drug Administration. Best Pharmaceuticals for Children Act. 2002. http: / / www.fda.gov/opacom/laws / pharmkids/contents.html. Accessed May 13, 2009. 
4. European Medicines Agency. Medicines for children. 2009. http:/ / www.emea.europa. $\mathrm{eu} / \mathrm{htms} / \mathrm{human} /$ paediatrics/introduction.htm. Accessed May 13, 2009.

5. Kunac DL, Kennedy J, Austin N, et al. Incidence, preventability and impact of adverse drug events (ADEs) and potential ADEs in hospitalized children in New Zealand: a prospective observational cohort study. Pediatr Drugs. 2009;11(2):153-160.
6. WHO Collaborating Center for Drug Statistics Methodology. 2009. ATC/DDD Index. http://www.whocc.no/atcddd. Accessed May 13, 2012.

7. Mark SM, Pollack MM, Griffin AG, et al. Drug pricing model in a pediatric hospital. Am J Health Syst Pharm. 2006;63(14):13611366. 